\title{
Analysis of Air Pollutant Emission Inventory from Farm Tractor Operations in Korea ${ }^{+}$
}

\author{
Gyu-Gang Han ${ }^{1}$, Jun-Hyuk Jeon ${ }^{2}$, Myoung-Ho Kim ${ }^{2,3,4}$ and Seong-Min Kim ${ }^{1,2,3,4, *(1)}$ \\ 1 Department of Agricultural Convergence Technology, Graduate School, Jeonbuk National University, \\ Jeonju 54896, Korea; dt200v@jbnu.ac.kr \\ 2 Department of Agricultural Machinery Engineering, Graduate School, Jeonbuk National University, \\ Jeonju 54896, Korea; splinter9608@jbnu.ac.kr (J.-H.J.); myoung59@jbnu.ac.kr (M.-H.K.) \\ 3 Department of Bioindustrial Machinery Engineering, College of Agriculture and Life Sciences, \\ JeonBuk National University, Jeonju 54896, Korea \\ 4 Institute for Agricultural Machinery \& ICT Convergence, Jeonbuk National University, Jeonju 54896, Korea \\ * Correspondence: smkim@jbnu.ac.kr \\ + Presented at the 2nd International Electronic Conference on Applied Sciences, 15-31 October 2021; Available \\ online: https://asec2021.sciforum.net/.
}

check for

updates

Citation: Han, G.-G.; Jeon, J.-H.; Kim,

M.-H.; Kim, S.-M. Analysis of Air

Pollutant Emission Inventory from Farm Tractor Operations in Korea.

Eng. Proc. 2021, 11, 17. https://

doi.org/10.3390/ASEC2021-11187

Academic Editor: Nunzio Cennamo

Published: 15 October 2021

Publisher's Note: MDPI stays neutral with regard to jurisdictional claims in published maps and institutional affiliations.

Copyright: (C) 2021 by the authors. Licensee MDPI, Basel, Switzerland. This article is an open access article distributed under the terms and conditions of the Creative Commons Attribution (CC BY) license (https:// creativecommons.org/licenses/by/ $4.0 /)$.

\begin{abstract}
Due to the decline in the agricultural labor force and rapid aging of farmers, agricultural machinery is becoming larger, higher-performance, and diversified. In this study, an air pollutant emission inventory for agricultural tractors was analyzed and compared with the inventory developed by a national agency. Agricultural tractors include walking and riding tractors and, further, riding tractors were divided into three subcategories based on their engine size. In addition, tractor emissions were classified according to the usage time of each operation. Seven air pollutants, such as CO, NOx, SOx, TSP, VOCs $\left(\mathrm{PM}_{10}\right), \mathrm{PM}_{2.5}$, and $\mathrm{NH}_{3}$, were included in the inventory. The results showed that the total yearly emissions in 2017 were $3300 \mathrm{Mg}$, $9110 \mathrm{Mg}$, $4 \mathrm{Mg}$, $567 \mathrm{Mg}$, $522 \mathrm{Mg}$, $759 \mathrm{Mg}$, and $33 \mathrm{Mg}$ for $\mathrm{CO}, \mathrm{NOx}, \mathrm{SOx}, \mathrm{TSP}, \mathrm{VOC}, \mathrm{PM}_{10}, \mathrm{PM}_{2.5}$, and $\mathrm{NH}_{3}$, respectively. The most emitted air pollutant in the transporting operation using walking tractors is $\mathrm{NOx}$, and the amount of emission is $1023 \mathrm{Mg} / \mathrm{y}$. Riding tractors mainly emit a large amount of NOx, in the order of medium, large, and small tractors. The NOx emissions from medium, large, and small riding tractors are $1103 \mathrm{Mg} / \mathrm{y}, 676 \mathrm{Mg} / \mathrm{y}$, and $322 \mathrm{Mg} / \mathrm{y}$, respectively, from harrowing operations and are $445 \mathrm{Mg} / \mathrm{y}, 273 \mathrm{Mg} / \mathrm{y}$, and $130 \mathrm{Mg} / \mathrm{y}$, respectively, from tilling operations. The results also showed that the total pollutant emissions from tractors were increased $10 \%$ compared to the emission inventory developed by a national agency due to categorizing riding tractors into three subcategories. A geographic information system (GIS) was used to spatially assign air pollutant variables to 17 provinces and metropolitan cities in Korea.
\end{abstract}

Keywords: agricultural tractor; diesel emission inventory; air pollutant; geographic information system

\section{Introduction}

Tractors are the main power machines used in agricultural work. Farm tractors are used in a variety of agricultural operations, with most work equipment attached and used in agriculture. Tasks such as farmland cultivation, leveling, sowing, fertilizing, and composting will begin at the beginning of the year. During crop cultivation and harvesting, tractors perform tasks such as loading, bailing, and transportation. At the end of 2020, the total number of small, medium, and large tractors exceeded 300,000, and the diesel consumption of agricultural, free-tax oil in 2019 reached 824,935 kL [1,2].

The production process of agricultural products has a great impact on the environment. Most of the impact is related to mechanization, especially tractor emissions [3]. Agricultural machinery is an important non-road vehicle source that can emit multiple pollutants and make a primary and secondary contribution to air pollution [4].Non-road vehicles need a large quantity of fossil fuels and their emissions cause significant air pollution problems. These types of vehicles mostly use diesel fuel, which has proven to be a major source 
of nitrogen compounds (NOx) and particulate matter (PM) [5]. The engine of a tractor operating in agriculture burns a large amount of fuel and emits combustion gas [6].

Air pollutants, such as PM, NOx, CO, volatile organic compounds (VOCs), etc., emitted by agricultural machinery and diesel internal combustion engines have a great impact on the surrounding environment and human health $[7,8]$. Since the exhaust gas of the internal combustion engine is not applied when evaluating industrial indicators and economic indicators, it is not possible to immediately know the numerical values and influence. However, when the air that people breathe is polluted and agricultural products are cultivated on contaminated agricultural land or when polluted water is used, human health is adversely affected $[9,10]$.

Algirdas Janulevičius [6] collected data on engine load, fuel consumption, and operating modes to study emissions characteristics during tractor operations and presented the average fuel consumption and $\mathrm{CO}, \mathrm{CO}_{2}$, and NOx emissions of the engine. Daniela Lovarelli analyzed [11] air pollutants emitted from ploughing, spike harrowing, sowing, and rolling operations with an engine exhaust gases emissions analyzer $\left(\mathrm{CO}_{2}, \mathrm{CO}\right.$, and $\left.\mathrm{NOx}\right)$.

To calculate the emissions of air pollutants in agricultural machinery, the National Institute of Environmental Research of the Republic of Korea uses the Tier 3 methodology of the EMEP/EEA (European Monitoring and Evaluation Programme/European Environment Agency) Guidebook, which is technology stratified by equipment. The type and number of agricultural machinery holdings, average annual activity, load factor, average rated power, etc., determine the amount of agricultural machinery air pollutants emitted. The tractor holdings used to calculate the air pollution emissions of tractors is not classified according to small, medium, and large size; the total number of tractors is used, so the accuracy of emission drops. In addition, the average rated output is fixed at $33.1 \mathrm{~kW}$, which was studied in 1999, and does not reflect the average rated output due to the automation and upsizing of tractors. Reflecting these matters, this research intends to make advancement in the air pollution emissions of internal combustion engines of agricultural machinery.

In this study, the inventory of air pollutants generated by farm tractor operations, including walking and riding tractors, were calculated and analyzed. Riding tractors were further divided into three subcategories according to their engine power outputs for more precise investigation. Seven types of air pollutants, including $\mathrm{CO}, \mathrm{NOx}, \mathrm{SOx}$, total solid particle (TSP), $\mathrm{PM}_{2.5}, \mathrm{VOCs}$, and $\mathrm{NH}_{3}$, were calculated using the agricultural tractor inventory data and operating hours in 2017, and the spatial distribution of the pollutants was visualized by a geographic information system (GIS).

\section{Materials and Methods}

\subsection{Estimation Method of Air Pollutant Emissions and Emission Factor}

In this study, the emission of air pollutants, including CO, NOx, SOx, TSP, $\mathrm{PM}_{2.5}$, VOCs, and $\mathrm{NH}_{3}$, from farm tractors in the Korea was estimated for the year 2017 by using the EMEP/EEA's Tier 3 methodology. For air pollutants, including CO, NOx, TSP, $\mathrm{PM}_{2.5}$, VOCs, and $\mathrm{NH}_{3}$, the amount of emissions was calculated using the equation given below [12]:

$$
\mathrm{E}_{\mathrm{i}, \mathrm{j}, \mathrm{k}}=\sum\left\{\mathrm{N}_{\mathrm{i}, \mathrm{k}} \times \mathrm{HP}_{\mathrm{i}} \times \mathrm{LF} \times \mathrm{HRS}_{\mathrm{i}} \times \mathrm{EF}_{\mathrm{i}, \mathrm{j}}\right\}
$$

where, $E_{i, j, k}$ is the total amount of air pollutant emitted from a specific region $(\mathrm{kg} / \mathrm{y}) ; \mathrm{N}_{\mathrm{i}, \mathrm{k}}$ is the number of tractors in a specific region (each); $\mathrm{HP}_{\mathrm{i}}$ is the average rated power of tractor $(\mathrm{kw}) ; \mathrm{LF}$ is the load factor of agricultural practice $(=0.48) ; \mathrm{HRS}_{\mathrm{i}}$ is the average annual activity of tractors $(\mathrm{hr} / \mathrm{y}) ; \mathrm{EF}_{\mathrm{i}, \mathrm{j}}$ is the emission factor $(\mathrm{kg} /(\mathrm{kWh}-\mathrm{each})) ; \mathrm{i}$ is agricultural tractor type $(i=1, \ldots, 4) ; j$ is the type of air pollutant $(j=1, \ldots, 7)$; and $k$ is region $(k=1$, $\ldots, 17)$.

For SOx emissions, the fuel consumption coefficient, according to the rated output of the farm tractor, is applied to the sulfur content, and the emission factor is calculated by the following Equation (2):

$$
\mathrm{EF}_{\mathrm{i}}=\mathrm{FF}_{\mathrm{i}}(\mathrm{g} / \mathrm{kWh} \text {-each }) / 1000 \times \mathrm{m} \times \text { Fuel sulfur weight percent }(\%) / 100
$$


where $\mathrm{EF}_{\mathrm{i}}$ is emission factor $(\mathrm{kg} /(\mathrm{kWh}$-each $))$; $\mathrm{FF}_{\mathrm{i}}$ is fuel factor $(\mathrm{g} /(\mathrm{kWh}$-each $))$; $\mathrm{m}$ is constant $(=2.0)$ (grams of SOx formed from one gram of sulfur); and i is farm tractor type $(\mathrm{i}=1, \ldots, 4)$.

Table 1 shows the air pollutant emission factors of agricultural tractors.

Table 1. Emission factors of farm tractors.

\begin{tabular}{cccccccc}
\hline \multirow{2}{*}{ Machinery } & \multicolumn{7}{c}{ Emission Factor (kg/kWh-Unit) } \\
\cline { 2 - 8 } & $\mathbf{C O}$ & NOx & TSP & $\mathbf{P M}_{\mathbf{2 . 5}}$ & VOCs & $\mathbf{N H}_{\mathbf{3}}$ & SOx \\
\hline $\begin{array}{c}\text { Walking Tractor } \\
\text { (Power Tiller) }\end{array}$ & 6.80 & 13.60 & 1.36 & 1.251 & 0.48 & 0.00004 & 5.42 \\
\hline & & & & & & & 5.38 \\
Riding Tractor & 2.48 & 7.84 & 0.39 & 0.359 & 0.48 & 0.00003 & 5.30 \\
& & & & & & & 5.30 \\
\hline
\end{tabular}

\subsection{Average Annual Activity Hours of Agricultural Tractors}

Activity hours of agricultural tractors were obtained from the survey on the utilization of agricultural machinery and farm-work mechanization rates published by the Rural Development Administration (RDA) in Korea. Table 2 shows the types of agricultural tractors and the annual activity hours associated with various agricultural operations [13].

Table 2. Average annual activity hours for various operations of agricultural tractors.

\begin{tabular}{ccc}
\hline \multirow{2}{*}{ Operation Type $^{\mathbf{1}}$} & \multicolumn{2}{c}{ Average Activity Hours (hr/y) } \\
\cline { 2 - 3 } & Walking Tractor (Power Tiller) & Riding Tractor \\
\hline TL & 1.8 & 20.4 \\
LL & - & 16.1 \\
HW & 4.9 & 50.6 \\
FS & - & 8.1 \\
PP & 18.3 & - \\
CS & - & 6.1 \\
SY & 22.9 & - \\
LD & - & 30.6 \\
BL & - & 3.4 \\
TP & 41.3 & 15.9 \\
Others & 2.2 & 13.7 \\
Total & 91.4 & 164.8
\end{tabular}

${ }_{1}^{1}$ TL: Tilling, LL: Leveling, HW: Harrowing, FS: Fertilizer spreading, PP: Pumping, CS: Compost spreading, SY: Spraying, LD: Loading, BL: Baling, TP: Transporting.

\subsection{Number of Holdings and Average Rated Power of Agricultural Tractor}

The number of agricultural tractors was directly obtained from the Agricultural Machinery Holdings Survey yearbook [14]. As of 2017, the total number of agricultural machines, such as tractors, rice transplanters, combine harvesters, etc., registered in Korea was 1,918,745 units. Among them, agricultural tractors were 857,216 units, accounting for $45 \%$ of total agricultural machinery in Korea. The holding status of agricultural tractors is shown in Table 3.

Agricultural tractors include a two-wheeled walking tractor (power tiller) and a fourwheeled riding tractor. In this study, air pollutants emitted from walking and riding tractors were calculated and riding tractors were further divided into 3 subcategories according to their engine power outputs for more precise investigation. The riding tractor can be divided into small, medium, and large, according to the diesel engine power. The range of engine power for small, medium, and large riding tractors is less than $29.4 \mathrm{kw}$, equal and more than $29.4 \mathrm{kw}$ and less than $44.1 \mathrm{kw}$, and equal and more than $44.1 \mathrm{kw}$, respectively. 
Average rated power is defined as a weighted average value with a normal distribution and is calculated by the number of tractors and the rated power.

Table 3. Average rated power and the number of agricultural tractors in Korea, as of 2017.

\begin{tabular}{cccc}
\hline Machinery & Size $^{\mathbf{1}}$ (ARP Range) & $\begin{array}{c}\text { ARP }^{\mathbf{2}} \\
\mathbf{( k W})\end{array}$ & Unit (ea) \\
\hline Walking Tractor (Power Tiller) & - & 6.7 & 567,070 \\
\hline \multirow{2}{*}{ Riding Tractor } & $\mathrm{S}<29.4 \mathrm{~kW}$ & 23.0 & 73,403 \\
& $29.4 \mathrm{~kW} \leq \mathrm{M}<44.1 \mathrm{~kW}$ & 39.0 & 148,538 \\
& $44.1 \mathrm{~kW} \leq \mathrm{L}$ & 52.1 & 68,205 \\
\cline { 2 - 4 } & Subtotal & & 290,146
\end{tabular}

${ }^{1}$ S: Small, M: Medium, L: Large. ${ }^{2}$ ARP: Average rated power. ARP is defined as a weighted average value and calculated from the number of tractors and their rated power.

\subsection{Geographic Information System (GIS)}

To visualize the spatial distribution of total air pollutant emissions from agricultural tractors in Korea, a piece of open-source geographic information system (GIS) software (QGIS, Windows 10) was used for 9 provinces and 8 metropolitan cities.

\section{Results and Discussion}

The air pollutant emission inventory for agricultural tractor usage in Korea was refined by categorizing the rated power of tractors and the types of operation tractors routinely perform. Table 4 and Figure 1 show the calculated inventory. In 2017, yearly amounts of $\mathrm{CO}, \mathrm{NOx}$, SOx, TSP $\left(\mathrm{PM}_{10}\right), \mathrm{PM}_{2.5}, \mathrm{VOCs}$, and $\mathrm{NH}_{3}$ emitted from agricultural tractors were calculated as $3300 \mathrm{Mg}$, $9110 \mathrm{Mg}$, $4 \mathrm{Mg}, 567 \mathrm{Mg}, 522 \mathrm{Mg}$, $759 \mathrm{Mg}$, and $33 \mathrm{Mg}$, respectively. The yearly amounts of total air pollutants emitted from one unit of walking tractors and small, medium, and large riding tractors were estimated to be $7.0 \mathrm{~kg}, 20.5 \mathrm{~kg}$, $34.6 \mathrm{~kg}$, and $46.3 \mathrm{~kg}$, respectively.

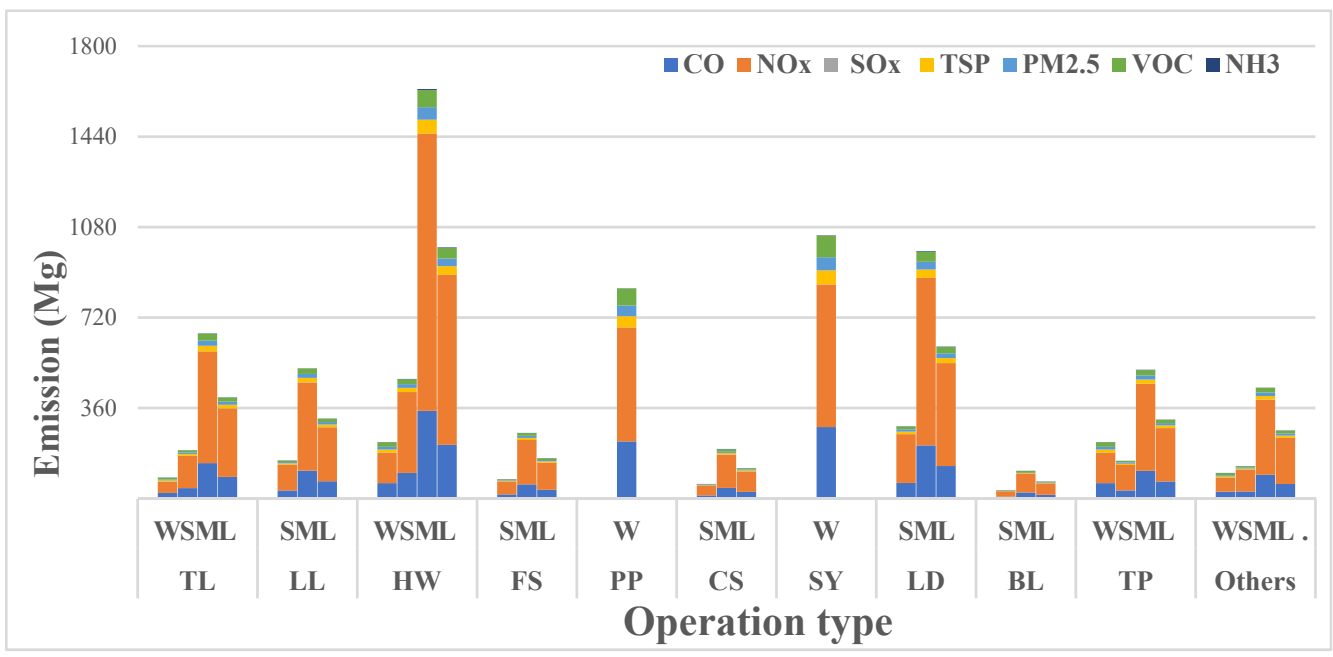

Figure 1. Calculated amount of air pollutant substance various farming practices by agricultural tractors. TL: Tilling, LL: Leveling, HW: Harrowing, FS: Fertilizer spreading, PP: Pumping, CS: Compost spreading, SY: Spraying, LD: Loading, BL: Baling, TP: Transporting, W: Walking tractor, S: Small riding tractor, M: Medium riding tractor, L: Large riding tractor.

Looking at the average activity hours by type of agricultural tractor, walking tractors are mainly used for transporting, pumping, and spraying operations, and riding tractors are mainly used for tilling, harrowing, and loading operations. As the area of cultivated land increases and the size of the tractor increases, the riding tractor replaces the tilling and 
harrowing operations that the walking tractor used to do in the past. The most emitted air pollutant in the transporting operations, which is the main work of the walking tractor, is NOx, and the amount of emission is $1023 \mathrm{Mg} / \mathrm{y}$, and the amount of emission of $\mathrm{PM}_{2.5}$, which is the main concern of air pollution, is $153.5 \mathrm{Mg} / \mathrm{y}$. Riding tractors mainly emit a large amount of $\mathrm{CO}$ and NOx, in the order of medium, large, and small tractors. The NOx emissions from medium, large, and small riding tractors are $1103 \mathrm{Mg} / \mathrm{y}, 676 \mathrm{Mg} / \mathrm{y}$, and $322 \mathrm{Mg} / \mathrm{y}$, respectively, from harrowing operations and are $445 \mathrm{Mg} / \mathrm{y}, 273 \mathrm{Mg} / \mathrm{y}$, and 130 $\mathrm{Mg} / \mathrm{y}$, respectively, from tilling operations. Utilization of riding tractors needs to be done efficiently to reduce air pollutant emissions, especially from harrowing operations.

Table 4. Calculated amounts of air pollutant substances emitted from agricultural tractor operations in 2017 (Mg/y).

\begin{tabular}{|c|c|c|c|c|c|c|c|c|}
\hline \multicolumn{2}{|c|}{ Machinery } & $\mathrm{CO}$ & NOx & $\begin{array}{c}\text { SOx } \\
\left(\times 10^{-2}\right)\end{array}$ & TSP & $\mathbf{P M}_{2.5}$ & VOCs & $\begin{array}{c}\mathrm{NH}_{3} \\
\left(\times 10^{-1}\right)\end{array}$ \\
\hline \multicolumn{2}{|c|}{$\begin{array}{l}\text { Walking Tractor } \\
\text { (Power Tiller) }\end{array}$} & 1132 & 2260 & 60.5 & 226 & 208 & 340 & 66.6 \\
\hline \multirow{4}{*}{$\begin{array}{l}\text { Riding } \\
\text { Tractor }\end{array}$} & Small & 332 & 1049 & 48.2 & 52.2 & 48.0 & 64.2 & 40.1 \\
\hline & Medium & 1137 & 3590 & 162.7 & 178.7 & 164.5 & 220 & 137.5 \\
\hline & Large & 697 & 2200 & 99.8 & 109.6 & 100.9 & 134.9 & 84.3 \\
\hline & Subtotal & 2170 & 6850 & 311 & 341 & 313 & 419 & 262 \\
\hline \multicolumn{2}{|c|}{ Total } & 3300 & 9110 & 371 & 567 & 522 & 759 & 329 \\
\hline
\end{tabular}

Our air pollutant emission inventory results for agricultural tractors were $10 \%$ more than those established by the NIER. The discrepancy could be due to the way values were assigned for the average rated power of riding tractors. The NIER method used a single value of $33.1 \mathrm{~kW}$ for all 209,149 tractors, while values of 23,39, and $52.1 \mathrm{~kW}$ were used to represent 73,403 small-size, 148,538 middle-size, and 68,205 large-size tractors, respectively, in this study. The spatial distribution of the total amount of air pollutant emissions from agricultural tractors in Korea was generated at the province/metropolitan city level using a GIS technique, as shown in Figure 2.
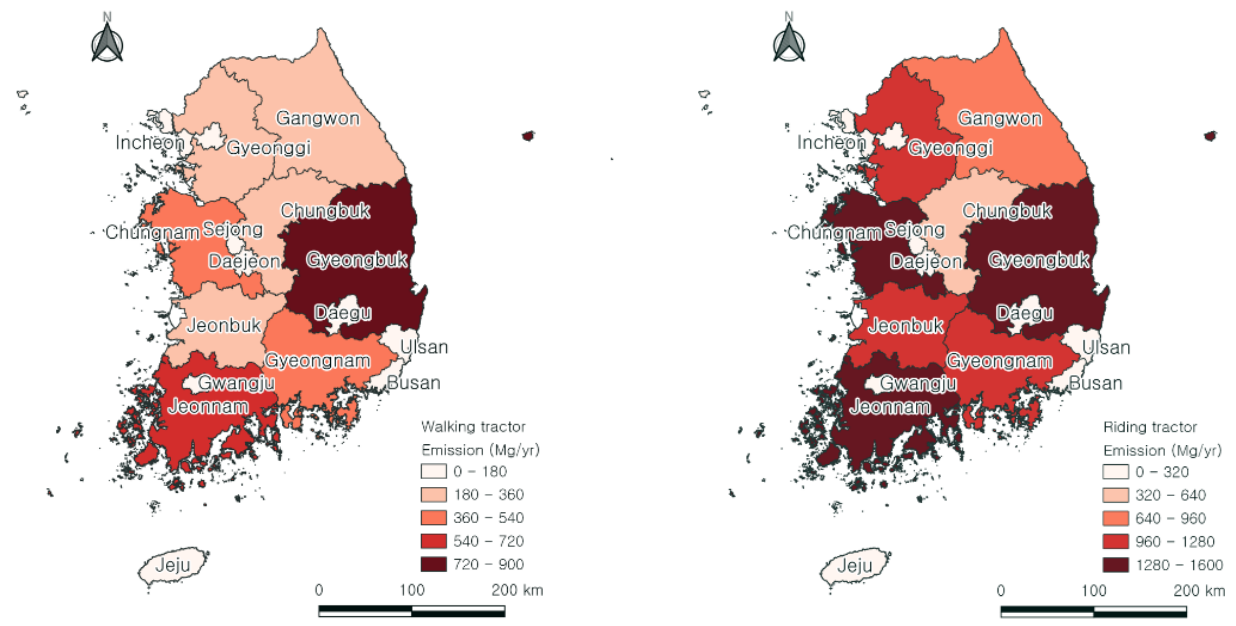

Figure 2. Spatial distribution of the total calculated air pollutant substance emitted from walking tractors (left) and riding tractors (right) over 9 provinces and 8 metropolitan cities in Korea.

\section{Conclusions}

In this study, the current air pollutant emission inventory of Korean agricultural tractors was refined by using the EEA Tier 3 methodology. The air pollutant emission inventory for agricultural tractor usage in Korea was calculated by categorizing the rated power of tractors into four subcategories. Yearly amounts of CO, NOx, SOx, TSP (including $\mathrm{PM}_{10}$ ), $\mathrm{PM}_{2.5}$, VOCs, and $\mathrm{NH}_{3}$ emitted from agricultural tractors were calculated as $3298 \mathrm{Mg}$, 
$9110 \mathrm{Mg}, 3.7 \mathrm{Mg}$, $567 \mathrm{Mg}, 522 \mathrm{Mg}$, $756 \mathrm{Mg}$, and $33 \mathrm{Mg}$, respectively. Among the non-road vehicle pollutants calculated by the National Institute of Environmental Research (NIER) Air Policy Support System (CAPSS, Clean Air Policy Support System) in 2017, the emissions of agricultural machinery were $3018 \mathrm{Mg} / \mathrm{y}$ of $\mathrm{CO}, 8223 \mathrm{Mg} / \mathrm{y}$ of NOx, $3 \mathrm{Mg} / \mathrm{y}$ of SOx, $523 \mathrm{Mg} / \mathrm{y}$ of TSP (including $\mathrm{PM}_{10}$ ), $481 \mathrm{Mg} / \mathrm{y}$ of $\mathrm{PM}_{2.5}, 705 \mathrm{Mg} / \mathrm{y}$ of VOCs, and $29 \mathrm{Mg} / \mathrm{y}$ of $\mathrm{NH}_{3}$ [15]. Our air pollutant emission inventory results for agricultural tractors were $10 \%$ more than those established by the NIER. The discrepancy could be due to the way values were assigned for the average rated power of riding tractors.

Walking tractors emitted the most diesel emissions during transportation operation, and riding tractors emitted the most air pollutant emissions during the tilling and harrowing operations. In order to reduce the air pollutants emitted by inefficient agricultural operations, it is necessary to analyze agricultural practices utilizing agricultural tractors in detail. It is necessary to predict future air pollutant emissions through past agricultural tractor air pollutant inventory analysis.

Author Contributions: Conceptualization, G.-G.H. and S.-M.K.; software, G.-G.H.; validation, G.-G.H., M.-H.K. and S.-M.K.; investigation, J.-H.J.; resources, G.-G.H.; writing-original draft preparation, G.-G.H.; writing-review and editing, M.-H.K. and S.-M.K.; visualization, J.-H.J.; supervision, S.-M.K.; project administration, S.-M.K.; funding acquisition, S.-M.K. All authors have read and agreed to the published version of the manuscript.

Funding: This work was carried out with the support for "Study on Particulate Matter Outbreak Source Characteristics during Agricultural Practice and Inventory Integration (Project No. PJ01428301)" by Rural Development Administration, Korea.

Conflicts of Interest: The authors declare no conflict of interest.

\section{References}

1. MAFRA. Agricultural Machinery Holdings Survey 2020; Ministry of Agriculture, Food and Rural Affairs: Sejong, Korea, 2020; p. 10.

2. NHCF. Agricultural Cooperative Yearbook 2020; National Agricultural Cooperative Federation: Seoul, Korea, $2020 ;$ p. 209.

3. Bacenetti, J.; Lovarelli, D.; Facchinetti, D.; Pessina, D. An environmental comparison of techniques to reduce pollutants emissions related to agricultural tractors. Biosyst. Eng. 2018, 171, 30-40. [CrossRef]

4. $\quad$ Lang, J.; Tian, J.; Zhou, Y.; Li, K.; Chen, D.; Huang, Q.; Xing, X.; Zhang, Y.; Cheng, S. A high temporal-spatial resolution air pollutant emission inventory for agricultural machinery in China. J. Clean. Prod. 2018, 183, 1110-1120. [CrossRef]

5. Zhao, Y.; Qiu, L.P.; Xu, R.Y.; Xie, F.J.; Zhang, Q.; Yu, Y.Y.; Nielsen, C.P.; Qin, H.X.; Wang, H.K.; Wu, X.C.; et al. Advantages of a city-scale emission inventory for urban air quality research and policy: The case of Nanjing, a typical industrial city in the Yangtze River Delta, China. Atmos. Chem. Phys. 2015, 15, 12623-12644. [CrossRef]

6. Janulevicius, A.; Juostas, A.; Pupinis, G. Engine performance during tractor operational period. Energy Convers. Manag. 2018, 68, 11-19. [CrossRef]

7. Zhou, W.; Chen, C.; Lei, L.; Fu, R.; Sun, Y. Temporal variations and spatial distributions of gaseous and particulate air pollutants and their health risks during 2015-2019 in China. Environ. Pollut. 2021, 272, 116031. [CrossRef] [PubMed]

8. Beak, K.M.; Kim, M.J.; Kim, J.Y.; Seo, Y.K.; Beak, S.O. Characterization and health impact assessment of hazardous air pollutants in residential areas near a large iron-steel industrial complex in Korea. Atmos. Pollut. Res. 2020, 11, 1754-1766. [CrossRef]

9. Kim, L.S.; Jeon, J.W.; Son, J.Y.; Kim, C.S.; Ye, J.; Kim, H.J.; Lee, C.H.; Hwang, S.M.; Choi, S.D. Nationwide levels and distribution of endosulfan in air, soil, water, and sediment in South Korea. Environ. Pollut. 2020, 265, 115035. [CrossRef] [PubMed]

10. Enyoh, C.E.; Verla, A.W.; Qingyue, W.; Ohiagu, F.O.; Ohiagu, F.O.; Chowdhury, A.H.; Enyoh, E.C.; Chowdhury, T.; Verla, E.N.; Chinwendu, U.P. An overview of emerging pollutants in air Method of analysis and potential public health concern from human environmental exposure. Trends Environ. Anal. Chem. 2020, 28, e00107. [CrossRef]

11. Lovarelli, D.; Fiala, M.; Larsson, G. Fuel consumption and exhaust emissions during on-field tractor activity: A possible improving strategy for the environmental load of agricultural mechanization. Comput. Electron. Agric. 2018, 151, 238-248. [CrossRef]

12. NIER. A Handbook of Method for National Air Pollutant Emission Estimation; National Institute of Environmental Research: Sejong, Korea, 2013; pp. 199-203.

13. RDA. Survey on the Utilization of Agricultural Machinery and Farmwork Mechanization Rate; Rural Development Administration: Jeonju, Korea, 2018; pp. 23-27.

14. MAFRA. Agricultural Machinery Holdings Survey 2017; Ministry of Agriculture, Food and Rural Affairs: Sejong, Korea, 2017 ; p. 12.

15. National Air Pollutants Emission Service. Available online: https://airemiss.nier.go.kr/user/boardList.do?handle=160\&siteId= airemiss\&id=airemiss_030500000000 (accessed on 5 May 2021). 